\title{
ELEMENTOS PARA DETERMINAR SI EL REGURSO DE INAPLICABILIDAD POR INCONSTITUCIONALIDAD DE FORMA DE "TODO PRECEPTO LEGAL CONTRARIO A LA CONSTITUCIÓN" TAMBIÉN QUEDA COMPRENDIDO DENTRO DE LA ÓRBITA DE APLICACIÓN DEL ARTÍCULO 80 DE LA CARTA FUNDAMENTAL
}

\author{
PAUlino VARAS ALFONSO \\ Profesor Titular de Derecho Constitucional \\ Facultad de Derecho - Universidad de Chile
}

SUMARIO

Introducción. I. La historia fidedigna del establecimien to del artículo 80 de la Constitución en el Consejo de Estado. II. El recurso de inaplicabilidad en el proyecto de reforma constitucional del Presidente Jorge Alessandri Rodríguez de julio de 1964. III. La supremacía de la Constitución y la vinculación directa de los preceptos constitucionales a las autoridades públicas y a todas las personas, como dos principios básicos del régimen democrático y constitucional. IV. El principio de legalidad ante el Honorable Senado. V. De cómo concurren a la formación de las leyes el Presidente de la República y ambas ramas del Consejo Nacional. VI. El juramento o promesa de cumplir la Constitución y las leyes del Presidente de la República, Senadores y Diputados, Ministros de la Corte Suprema y de las Cortes de Apelaciones, Jueces de Letras, miembros del Tribunal Calificador de Elecciones y Ministros de Estado. VII. La Constitución es un todo orgánico. VIII. Del sentido natural y obvio de las expresiones "todo precepto legal contrario a la Constitución". IX. Conclusión

\section{INTRODUCGIÓN}

El presente trabajo tiene por objeto destacar algunos elementos que permitan establecer si el recurso dé inaplicabilidad por inconstitucionalidad de forma 
de todo precepto legal contrario a la Constitución también queda comprendido dentro de la órbita de aplicación del artículo 80 de la Carta Fundamental, luego que en la sentencia de 31 de marzo de 1995 del Tribunal Pleno de la Corte Suprema se produjera un virtual empate acerca de la procedencia de dicho recursol.

\section{IA HISTORIA FIDEDIGNA DEL ESTABLECIMIENTO DEL ARTICULO 80 DE LA CONSTITUCIÓN EN EI, CONSEJO DE ESTADO}

En la octogésima quinta (85a.) sesión, celebrada el 14 de agosto de 1979 por el Consejo de Estado, se da lectura al artículo 86 (actual artículo 80) y se dice textualmente:

"Como algunos señores Consejeros opinan que la declaración de inaplicabilidad debería tener carácter general, don Enrique Lrutia recuerda que el precepto pertinente de la Constitución de 1925 fue el resultado de una transacción, pues se consideró impropio que la Corte Suprema quedara por encima del Congreso y pudiera dejar sin efecto lo dispuesto por éste. El señor Ortúzar observa que una norma contenida en el capitulo referente

${ }^{1}$ Se trata de Compañia Minera Tamaya S.A., publicada en Revista de Derecho y Jurisprudencia t. 92 (1995) 2.5, 83-105; hay sentencia recaida en recurso de aclaración, de 24.4.1996, cuyo texto es el siguiente:

"Vistos y teniendo presente:

Que si bien es cierto que en la sentencia dictada en estos autos se produjo empate a seis votos en lo relativo a la admisibilidad del recurso de inaplicabilidad en cuanto éste se basaba en causales de inconstitucionalidad formal, tal igualdad de pareceres ha resultado irrelevante porque no es menos cierto que en lo concerniente a la decisión de rechazar dicho recurso, tanto en sus fundamentos formales como de fondo, existió una mayoría de ocho votos contra cuatro, según aparece claramente de la misma sentencia.

Por otra parte, no corresponde a esta Corte pronunciarse sobre la situación en la que quedará la resolución del Tribunal Constitucional de seis de septiembre de mil novecientos ochenta y tres que se menciona en la letra b) de la petición de aclaración y agregación.

Por estos fundamentos se declara sin lugar el recurso de aclaración de fs. 114 . Rol № 20.135". 
al Tribunal Constitucional permite a éste determinar una inaplicabilidad de carácter general, si la Corte Suprema, en tres fallos sucesivos, concluye que un texto legal es contrario a la Constitución.

"Don Julio Philippi es partidario de no modificar la redacción propuesta al paso que don Pedro Ibáñez se declarara en favor de que la inaplicabilidad tenga efectos generales. Intervienen además el señor Presidente y los Consejeros señores Ortúzar, Coloma, Figueroa y Humeres, y se llega al acuerdo de dejar pendiente el artículo 86 hasta que se estudie el capítulo relativo al Tribunal Constitucional".

En la octogésima sexta sesión (86a.), celebrada el 21 de agosto de 1979 , se lee textualmente:

"El señor Presidente recuerda la experiencia que tuvo como gobernante, cuando se vio forzado a promulgar una ley que había sido despachada por el Congreso, con infracción, a su juicio, de las normas que reglaban su tramitación. El señor Philippi toma este ejemplo y lo califica como un caso típico de lo que es un vicio "interna corporis", es decir, de un problema interno producido en la elaboración de la ley, el que, por ser de forma y no de fondo, podría ser conocido por un Tribunal Constitucional, pero no por la Corte Suprema a través de un recurso de inaplicabilidad. Considera inconveniente sacar a esta última de su papel de tribunal encargado de aplicar el derecho, y puntualiza que la facultad de desconocer una ley, cuando está viciada en los procesos de promulgación, publicación o cuando presenta omisiones manifiestas, corresponde a cualquier juez de la República, pero que otras demasías, como la de que una ley tenga origen en una rama del Congreso, debiendo tenerla en la otra, es materia propia de un Tribunal Constitucional y no de la Corte Suprema.

"El señor Humeres comparte el criterio de don Julio Philippi, en razón de la experiencia que tuvo en la Contraloría General de la República, la que siempre opinó que debía existir un cuerpo que resolviera en forma preventiva problemas como los aludidos, pues siempre es más fácil corregir un defecto de forma cuando se está tramitando un proyecto que después, cuando ya es un hecho consumado. Coincide también con la idea del señor Presidente de que la inaplicabilidad de una ley, cuando es inconstitucional, sea del resorte exclusivo de la Corte Suprema, y de que si una declaración en tal sentido se reitera en tres fallos a lo menos tenga aplicación general, planteamiento en que lo acompañan los Consejeros señores Ortúzar y Philippi. Este último subraya la conveniencia de que la citada Corte se limite a las inconstitucionalidades de fondo, dejando a la doctrina las inconstitucionalidades de forma, pues lo contrario sería peligroso, ya que si la Corte Suprema incur- 
sionara en el ajetreo de las indicaciones y contraindicaciones, entraria a un terreno político muy movido.

"Don Enrique Ortúzar expresa que si hubiese acuerdo en el modo como se ha planteado el problema, sería preciso ampliar el artículo 86 del anteproyecto, que se dejó pendiente, facultando a la Corte Suprema para declarar la inconstitucionalidad de una ley, en los casos en que tres fallos sucesivos dictados por ella hayan señalado que se trata de preceptos contrarios a la Constitución. Obviamente, agrega, dentro del concepto de ley quedarán comprendidos los decretos con fuerza de ley y los decretos leyes. Sugiere que se faculte a la mesa para darle al artículo la redacción correspondiente. Así se acuerda proceder.

En la misma sesión 86 y con motivo de las atribuciones del Tribunal Constitucional el señor Philippi "estima que todo el conjunto debe estudiarse con mayor detenimiento, más aún cuando se plantean dudas en cuanto al alcance que estas disposiciones pudieran tener, segün si se plantea la inconstitucionalidad de forma o la de fondo, punto sobre el cual expresan distintos pareceres los Consejeros señores Urrutia, Ortúzar, Carmona e Ibáñez.

"Se acuerda, también, que en el estudio del artículo 86, que quedó pendiente en la última sesión, deberá tenerse presente el texto de la reforma constitucional propuesta por el Presidente don Jorge Alessandri en julio de 1964. Al respecto, el señor Philippi reitera que, en virtud del principio "interna corporis", el Poder Judicial no puede decidir que, al tramitarse un determinado proyecto de ley, no se han cumplido los procedimientos constitucionales o reglamentarios de las Cámaras. En la centésima tercera sesión (103a.), celebrada el 29 de enero de 1980 y sin que se realizara un nuevo estudio se aprobó el artículo 86, actual 80, con la redacción que hoy tiene.

\section{EL RECURSO DE INAPLICABILIDAD EN EL PROYECTO DE REFORMA CONSTITUCIONAL DEL PRESIDENTE JORGE ALESSANDRI RODRÍGUEZ DE JULIO DE 1964}

Dicho Proyecto de Reforma Constitucional en su parte considerativa, refiriéndose a la proposición de un nuevo texto del artículo 86 (actual 80) señalaba: "La facultad de la Corte Suprema, de acuerdo con este artículo, para declarar inaplicable un precepto legal por ser contrario a la Constitución, que hoy puede ejercer en los casos particulares de que conoce, se sustituye y amplía en forma de que la Corte Suprema, a petición de cualquier ciudadano, deberá declarar inconstitucional cualquier precepto legal contra- 
rio a la Constitución Política del Estado, sea en la forma de su generación o en su contenido de fondo. Esta petición deberá fallarse dentro de treinta días de interpuesta.

"Acogido el recurso de inconstitucionalidad, la Corte Suprema ordenará publicar de inmediato el fallo respectivo en el Diario Oficial y a partir de la fecha de esta publicación el precepto inconstitucional dejará de producir efectos, sin que esta declaración pueda afectar las sentencias ejecutoriadas dictadas con anterioridad a dicha publicación.

"Esta modificación -que también fue propuesta por el Presidente de la República al discutirse la reforma constitucional del año 1925-, está destinada a someter los actos del Congreso Nacional a normas semejantes a las que prevalecen para los demás poderes públicos y evitar la extralimitación en sus facultades por parte de aquél".

En virtud de las consideraciones transcritas, dicho proyecto sometía al Congreso Nacional el siguiente nuevo artículo 86:

"Artículo 86.- Sustitúyese el inciso $2^{\circ}$ por los siguientes:

"La Corte Suprema a petición de cualquier ciudadano deberá declarar inconstitucional cualquier precepto legal contrario a la Constitución Política del Estado, sea en la forma de su generación o en su contenido de fondo".

"Esta petición deberá fallarse dentro de 30 días hábiles de interpuesta”.

"Acogido el recurso de inconstitucionalidad, la Corte Suprema ordenará publicar de inmediato el fallo respectivo en el 'Diario Oficial' y, a partir de la fecha de esa publicación, el precepto inconstitucional dejará de producir efectos sin que esta declaración pueda afectar las sentencias ejecutoriadas dictadas con anterioridad a dicha publicación".

\section{LA SUPREMACÍA DE LA CONSTITUCIÓN YLA VINCULACIÓN DIRECTA DE LOS PRECEPTOS CONSTITUCIONALES A LAS AUTORIDADES PÚBLICAS Y A TODAS LAS PERSONAS, COMO DOS PRINCIPIOS BÁSICOS DEL RÉGIMEN DEMOCRÁTICO Y CONSTITUCIONAL.}

El Tribunal Constitucional en la sentencia de 27 de noviembre de 1983, recaída en el Rol № 19 (Considerando 10), estableció que "el artículo $6^{\circ}$ de la Constitución comprende dos conceptos fundamentales. En sus incisos primero y segundo consagra principios vitales en los cuales descansa la nueva institucionalidad, como son: el de la "supremacía constitucional" sobre todas 
las otras normas jurídicas que integran nuestro ordenamiento positivo y el de la "vinculación directa" de los preceptos constitucionales a las autoridades públicas, y a todos los ciudadanos, siendo, por ende, tales preceptos obligatorios, tanto para los gobernantes como para los gobernados. De allí que primero se establezca que "Los órganos del Estado deben someter su acción a la Constitución y a las normas dictadas conforme a ella". Y, acto seguido, se agregue que "Los preceptos de esta Constitución obligan tanto a los titulares o integrantes de dicho órgano, como toda persona, institución o grupo".

El Tribunal Constitucional en la sentencia de 7 de diciembre de 1994, Rol N² 190, considerando 14, letra c), expresa textualmente:

"En virtud del principio de la supremacía constitucional sobre todas las otras normas jurídicas que integran nuestro ordenamiento positivo, expresamente consagrado en los incisos primero y segundo del artículo $6^{\circ}$ de nuestra Carta Fundamental al disponer el primero que "Los órganos del Estado deben someter su acción a la Constitución y a las normas dictadas conforme a ella", y el segundo que "Los preceptos de esta Constitución obligan tanto a los titulares o integrantes de dichos órganos como toda persona, institución o grupo", (es) uno de los principios vitales en que descansa la nueva institucionalidad según lo expresa este Tribunal en causa Rol № 19".

\section{EL PRINCIPIO DE LEGALIDAD ANTE EL HONORABLE SENADO}

La Comisión de Constitución, Legislación, Justicia y Reglamento del H. Senado en los informes de 28 de julio de 1994 (Boletín № $5170-03$ ) y de 26 de abril de 1995 (Boletines Nos $5148-03$ y 5164-03), respectivamente, aprobados ambos por la Sala en sesiones de 9 de noviembre de 1994 y 6 de junio de 1995, ha resuelto textualmente (Considerando № 1):

"1.- Que la Constitución Política consagra en su Capítulo I, "Bases de la Institucionalidad", el principio de legalidad.

En efecto, el artículo $6^{\circ}$ dispone, en la parte pertinente, que "los órganos del Estado deben someter su acción a la Constitución y a las normas dictadas conforme a ella".

El artículo $7^{\circ}$, por su parte, establece que "los órganos del Estado actúan válidamente previa investidura regular de sus integrantes, dentro de su competencia y en la forma que prescriba la ley", agregando que "ninguna magistratura, ninguna persona ni grupo de personas pueden atri- 
buirse, ni aun a pretexto de circunstancias extraordinarias, otra autoridad o derechos que los que expresamente se les hayan conferido en virtud de la Constitución o las leyes". Finalmente, añade que "todo acto en contravención a este artículo es nulo y originará las responsabilidades y sanciones que la ley señale".

\section{DE CÓMO CONCURREN A LA FORMACIÓN DE I AAS I.EYES EL PRESIDENTE DE LAA REPÚBLICA Y AMBAS RAMAS DEL CONGRESO NACIONAL}

El artículo 32 de la Carta Fundamental establece que la primera atribución especial del Presidente de la República es "Concurrir a la Formación de las Leyes con arreglo a la Constitución, sancionarlas y promulgarlas".

Por su parte, el artículo 42 de la Ley Suprema establece que "El Congreso Nacional se compone de dos ramas: La Cámara de Diputados y el Senado. Ambas concurren a la formación de las leyes en conformidad a esta Constitución y tienen las demás atribuciones que ella establece".

\section{EL JURAMENTO O PROMESA DE CUMPIIR LA CONSTITUCIÓN Y LAS LEYES DEL PRESIDENTE DE LA REPÚBLICA, SENADORES Y DIPUTADOS, MINISTROS DE LA CORTE SUPREMA Y DE LAS CORTES DE APELACIONES, JUECES DE LETRAS, MIEMBROS DEL TRIBUNAL CALIFICADOR DE ELECCIONES Y MINISTROS DE ESTADO}

La Constitución en su artículo 27 establece que "El Presidente electo prestará ante el Presidente del Senado, juramento o promesa de desempeñar fielmente el cargo de Presidente de la República, conservar la Independencia de la Nación, guardar y hacer guardar la Constitución y las leyes y de inmediato asumirá sus funciones".

La Ley Orgánica Constitucional del Congreso Nacional № 18.918, establece en su artículo $1^{\circ}$ que "La composición, generación, atribuciones y funcionamiento de la Cámara de Diputados, del Senado y del Congreso Nacional, se regirán por la Constitución Política y las leyes orgánicas constitucionales que correspondan" y el artículo $5^{0}$ de la misma ley orgánica constitucional establece en sus incisos $1^{\circ}, 2^{\circ}$ y $3^{\circ}$ lo siguiente: 
"El Congreso Nacional deberá instalarse el día 11 de marzo siguiente a una elección de senadores y diputados.

"Se entenderá instalado el Congreso Nacional luego de la investidura de la mayoría de los miembros de cada Cámara y de que hayan sido elegidos los integrantes de las respectivas mesas.

"La investidura de los senadores y diputados se hará inmediatamente bajo juramento o promesa, de acuerdo con el procedimiento que establezcan los reglamentos de las Cámaras y desde ese momento se consideran en ejercicio".

Por su parte, el Reglamento del Honorable Senado, publicado en el Diario Oficial de 20 de abril de 1993 , establece en su artículo $4^{\circ}$ lo siguiente:

Los nuevos senadores prestarán juramento o promesa individual ante el Presidente, con arreglo a la siguiente fórmula:

“Juráis o prometéis guardar la Constitución Política del Estado; desempeñar fiel y lealmente el cargo que os ha confiado la Nación, consultar en el ejercicio de vuestras funciones sus verdaderos intereses según el dictamen de vuestra conciencia y guardar sigilo acerca de lo que se trate en sesiones secretas?".

El nuevo senador responderá: "Sí, juro", después de lo cual el Presidente agregará: "Si así lo hiciéreis, Dios os ayude, y si no, Él y la Patria os hagan cargo", o "Sí prometo", en cuyo caso el Presidente agregará: "Si así lo hiciéreis la Patria os lo agradezca y si no que ella os lo demande".

Enseguida el Presidente lo declarará incorporado a la Sala.

Durante el acto todos los presentes permanecerán de pie”.

El Reglamento de la Cámara de Diputados aprobado por resolución de su Presidente publicada en el Diario Oficial de 20 de mayo de 1994, establece en su artículo 31 lo siguiente:

"Los Diputados, al incorporarse a la Cámara, prestarán juramento o promesa ante el Presidente, con arreglo a la siguiente fórmula: “Juráis o prometéis guardar la Constitución Política, desempeñar fiel o legalmente el cargo que os ha confiado la Nación, consultar en el ejercicio de vuestras funciones sus verdaderos intereses y guardar sigilo acerca de lo que se trate en sesiones secretas?".

El Diputado contestará: "Sí, juro", o "Sí, prometo", después de lo cual el Presidente lo declarará incorporado a la Sala.

En el acto de prestarse juramento o promesa, se pondrán de pie los Diputados y demás personas presentes".

El Código Orgánico de Tribunales, en su Título X denomina- 
do "De los Magistrados y de los Nombramientos", párrafo IV "De la instalación de los jueces", establece en su artículo 299 que "Hecho el nombramiento de un juez por el Presidente de la República y expedido el correspondiente título a favor del nombrado, prestará éste el juramento prevenido en los artículos siguientes".

Yel artículo 300 señala que:

"Los miembros de la Corte Suprema prestarán su juramento ante el Presidente del mismo Tribunal".

"Los de las Cortes de Apelaciones ante el Presidente del respectivo Tribunal".

"Ante el mismo funcionario lo prestarán también los Jueces de

Letras".

El Código Orgánico de Tribunales agrega en su artículo 304 que "Todo Juez prestará su juramento al tenor de la fórmula siguiente: "¿Juráis por Dios Nuestro Señor y por estos Santos Evangelios que, en ejercicio de vuestro Ministerio, guardaréis la Constitución y las leyes de la República?".

El interrogado responderá: "Sí, juro", y el Magistrado que le toma el juramento añadirá: "Sí así lo hiciéreis, Dios os ayude, y si no, os lo demande".

Finalmente, el artículo 305 del mismo Código establece que "Prestado que sea el juramento, se hará constar la diligencia en el libro respectivo, y de ella se dará testimonio al nombrado, el cual entrará inmediatamente en el ejercicio de sus funciones.

La Ley Orgánica Constitucional del Tribunal Constitucional № 17.997 establece en su artículo 10 que "el Presidente y los Ministros prestarán juramento o promesa de guardar la Constitución y las leyes de la República, ante el Secretario del Tribunal" y agrega que "del juramento o promesa se dejará constancia en un libro especial".

Por su parte, la Ley Orgánica Constitucional sobre el Tribunal Calificador de Elecciones establece en el inciso final del artículo $2^{\circ}$ que "Los miembros del Tribunal Calificador de Elecciones prestarán juramento o promesa de cumplir la Constitución y las leyes ante el Secretario relator del Tribunal".

Aun cuando no existe ley alguna que establezca el juramento de los Ministros de Estado, existe una tradición más que centenaria que consiste en que el nombrado Ministro de Estado comparezca ante S.E. el Presidente de la República para prestar el juramento de estilo, e interrogado al efecto por S.E. en los siguientes términos: 
"Juráis desempeñar fielmente el cargo que se os ha conferido y cumplir en su ejercicio la Constitución y las leyes?".

Contestó: "Sí, juro".

Luego del juramento, se da por terminado el acto, firmando el Ministro con el Subsecretario del Interior.

\section{LA CONSTITLCIÓN ES LN TODO ORGÁNICO}

Ésta es una norma vital de hermenéutica constitucional que consiste en que la Constitución es un todo orgánico y el sentido de sus normas debe ser determinado de manera tal que exista entre ellos la debida correspondencia y armonía. En efecto, por sentencia del Tribunal Constitucional de 24 de septiembre de 1985, recaída en el Rol № 33, se resolvió que "La Constitución es un todo orgánico y el sentido de sus normas debe ser determinado de manera tal que exista entre ellas la debida concordancia y armonía, excluyéndose cualquiera interpretación que conduzca a anular o a privar de eficacia algún precepto de ella". Esta jurisprudencia aparece ratificada en las sentencias del Tribunal Constitucional de 21 de diciembre de 1987 y de 12 de diciembre de 1989 , causas Roles №s. 66 y 67 , respectivamente.

Esta norma de hermenéutica significa que debe desecharse de plano toda interpretación de la Constitución que deje sin aplicación los preceptos que ella establece para la formación de la ley.

\section{DEL SENTIDO NATURAL Y OBVIO DE LAS EXPRESIONES "TODO PRECEPTO LEGAL CONTRARIO A LA CONSTITUCIÓN"}

El adjetivo "todo" proviene del latín "totus" y según el diccionario de la Lengua Española, vigésima primera edición de 1992, es aquello que "Dícese de lo que se toma o se comprende enteramente en la entidad o en el número" y además, "Seguido de un sustantivo en singular y sin artículo, toma y da a este sustantivo valor de plural. TODO fiel cristiano, equivalente a TODOS los fieles cristianos; TODO delito, equivalente a TODOS los delitos". De modo que al establecer el artículo 80 de la Constitución que la Corte Suprema podrá declarar inaplicable "TODO precepto legal contrario a la Constitución" resulta forzoso concluir que dicha norma "comprende enteramente" a "TODOS los preceptos legales contrarios a la Constitución", sea que adolezcan de vicios de forma o de fondo. 


\section{CONCLUSIÓN}

Las consideraciones precedentes permiten afirmar que la Constitución Política de la República debe aplicarse en todas sus partes y que los órganos colegisladores deben ajustarse estrictamente a los preceptos constitucionales sobre la formación de la ley, razón por la cual debe concluirse que el recurso de inaplicabilidad por inconstitucionalidad de forma de "todo precepto legal contrario a la Constitución" también queda comprendido dentro de la órbita de aplicación del artículo 80 de la Carta Fundamental. 